\title{
Androgen receptor gene exon 1 CAG repeat polymorphism in Finnish patients with childhood-onset type 1 diabetes
}

\author{
Zsofia Gombos ${ }^{1,2}$, Robert Hermann ${ }^{1,2}$, Riitta Veijola ${ }^{4}$, Mikael Knip ${ }^{1,5,6}$, Olli Simell ${ }^{1,3}$, Pasi Pollanen ${ }^{7}$ \\ and Jorma Ilonen ${ }^{1,2}$ \\ ${ }^{1}$ JDRF Centre for Prevention of Type 1 Diabetes in Finland, Departments of ${ }^{2}$ Virology and ${ }^{3}$ Paediatrics, University of Turku, Turku, Finland, \\ ${ }^{4}$ Department of Paediatrics, University of Oulu, Oulu, Finland, ${ }^{5}$ Hospital for Children and Adolescents, University of Helsinki, Helsinki, Finland, \\ ${ }^{6}$ Department of Paediatrics, Tampere University Hospital, Tampere, Finland and ${ }^{7}$ Department of Anatomy, Institute of Biomedicine, University of Turku, \\ Turku, Finland \\ (Correspondence should be addressed to Z Gombos, Department of Virology, University of Turku, Kiinamyllynkatu 13, FIN-20520 Turku, Finland; \\ Email: zsogom@utu.fi)
}

\begin{abstract}
Objective: Animal models suggest that androgen receptor gene polymorphisms might affect disease predisposition in human immune-mediated diabetes. The aim of this study was to investigate the effect of the human androgen receptor gene exon 1 CAG repeat polymorphisms on type 1 diabetes (T1D) susceptibility.

Design and methods: A combined strategy of case-control and family-based approaches was used. Affected sibling pair families $(n=120)$, nuclear families $(n=645)$ and cohorts of sporadic cases $(n=208)$ and controls $(n=1381)$ were genotyped for androgen receptor gene exon 1 CAG repeat polymorphism. An automated fluorescence-based DNA fragment-sizing method was used.

Results: The distribution of CAG repeat alleles did not differ significantly between patients and controls. However, short repeat alleles $(7-14)$ were more prevalent among cases in girls compared with controls $(8.77 \%$ vs $5.91 \% ; P=0.03)$. Long repeat alleles $(19-28)$ were less frequent among HLA DR3-positive diseased boys than in DR3-positive control boys $(32.6 \%$ vs $40.6 \% ; P=0.011)$. The differences were not significant after adjustment for multiple comparisons. Transmission of CAG repeat alleles was not different from expected in the total material. However, transmissions to girls deviated from the expected value significantly (extended transmission disequilibrium test (ETDT) $37.82 ; P=0.0016$ ). A decreased transmission of the alleles with 13,20 and 26 repeats to girls was observed (T\%0, $P=0.046 ; \mathrm{T} \% 25.5, P=0.0003$, T\%0, $P=0.025$ ).

Conclusion: The results do not support a common role for the androgen receptor gene exon 1 CAG repeat in T1D susceptibility; however, an effect of a disease variant in linkage disequilibrium could be detected.
\end{abstract}

European Journal of Endocrinology 149 597-600

\section{Introduction}

Autoimmune disorders are, in general, more common in women than in men (1). This sex-specific difference has been implicated as reflecting the effect of sex steroids on immune responses, particularly the immune suppressive effects of androgens (2). Type 1 diabetes (T1D) makes an exception from the gender rule, as the disease tends to be more prevalent in men (the male:female ratio is $1.1: 1.7)(3,4)$.

The target organ response to androgens is determined mainly by the androgen receptor (AR) (OMIM No. 313700, Xq11-q12), the activation of which induces expression of a multitude of genes (5). The AR gene is more than 90 kilobases in length and contains eight exons (6). The large amino-terminal domain is encoded by exon 1, which includes a highly polymorphic CAG repeat that is translated into a poly-glutamine stretch
(Fig. 1). In vitro, the length of the CAG repeats correlates inversely with the transactivating function of the AR $(7,8)$. The exon $1 \mathrm{CAG}$ repeat of the AR is associated with various disorders. A high number of CAG repeats (more than 40) considerably decreases receptor function and results in androgen insensitivity, oligospermic infertility and andropausal symptoms (9-12). In addition, long repeat alleles have been associated with Kennedy's disease, an X-linked spinal bulbar muscular atrophy (13). On the other hand, shorter repeats, although in the normal range (7-28), have been associated with increased androgen sensitivity which can lead to increased prostate cancer risk in males and anovulatory infertility in females $(14,15)$.

There are very limited data on the relationship of AR and human autoimmune diseases. It has been reported that a shorter exon 1 CAG repeat length is associated with rheumatoid arthritis in younger onset male 


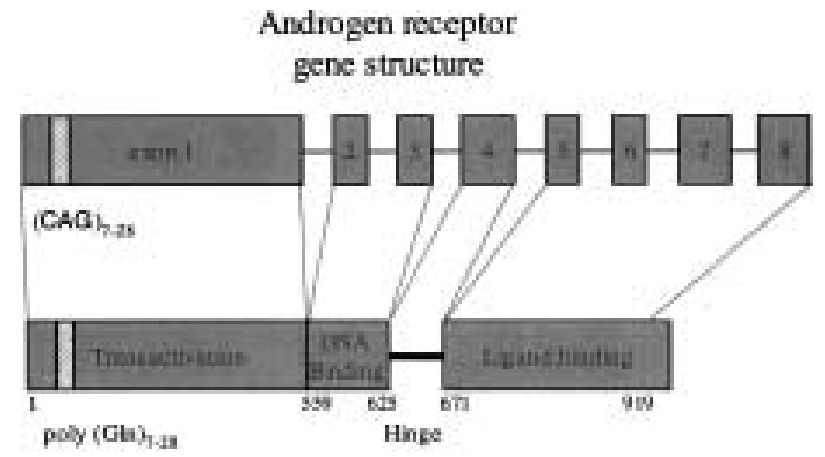

Protecin ștructure

Figure 1 Gene structure and functional domains of the androgen receptor (Xq11-12).

patients (16). In addition, data from animal studies suggest that androgen action might affect diabetes susceptibility in humans. It has been shown that androgen treatment prevents diabetes in non-obese diabetic mice; moreover, testosterone increased the circulating insulin levels and induced islet hypertrophy in rat and mouse diabetes models $(2,17,18)$. Mice transgenic to expanded CAG triplet repeats were prone to diabetes (19). The involvement of androgens in the pathogenesis of the beta-cell specific autoimmune process has not been confirmed in man. However, it is known that the age-specific T1D incidence curve has its highest peak during puberty, and after pubertal years an increase in the male to female incidence ratio can be seen $(20,21)$. These observations and the above mentioned experimental data suggest that androgen hormone action could be involved in be the pathogenesis of T1D.

The aim of the study was to investigate the linkage and association of a functional polymorphism of the androgen receptor gene with T1D.

\section{Subjects and methods}

\section{Subjects}

Two sets of families with affected children were analysed in this study. The first family set included 120 affected sibling pair families with two or more affected children. The second set comprised 645 nuclear families with one child affected by T1D and healthy parents. In addition, a cohort of sporadic cases was also analysed $(n=208)$. Most of the patients and families were collected from four university centres in Finland (Turku, Tampere, Oulu and Helsinki). All cases presented with classical T1D were diagnosed according to the World Health Organisation's criteria before the age of 15 years. Consecutively recruited healthy newborns from the same geographical regions were used as controls ( $n=1381 ; 891$ boys, 490 girls). The local Ethics Committees had approved the study and informed consent was obtained from the participating subjects and/or from their parents.

\section{Methods}

DNA was extracted from peripheral EDTA-blood using a salting out method (22). HLA DQA1-DQB1 genotypes were identified using a PCR-based lanthanide-labelled oligonucleotide hybridisation and time-resolved fluorometry detection method $(23,24)$. The androgen receptor (AR) gene (Xq11-12) exon 1 CAG repeat polymorphism was analysed using PCR where one primer was labelled with a fluorescent dye. After initial denaturation for $1 \mathrm{~min}$ at $96^{\circ} \mathrm{C}$, samples were subjected to 30 cycles of amplification, consisting of a $20 \mathrm{~s}$ denaturation phase at $96^{\circ} \mathrm{C}$, a $1 \mathrm{~min}$ annealing phase at $62^{\circ} \mathrm{C}$ and a $1 \mathrm{~min}$ extension phase at $72^{\circ} \mathrm{C}$. The forward primer was: $5^{\prime}$ AGA ATC TGT TCC AGA GCG TGC $3^{\prime}$, and the reverse primer was: $5^{\prime} \mathrm{GAC}$ TGC GGC TGT GAA GGT TGA $3^{\prime}$ labelled with HEX dye. The AR gene exon 1 CAG repeat alleles were identified by fluorescence-based automated DNA fragment sizing according to the manufacturer's instructions (MegaBace 1000, Amersham Biosciences, CA, USA).

\section{Statistics}

Transmission disequilibrium test (TDT) and linkage analysis were carried out using TDTPHASE (developed by Frank Dudbridge, 2000), MapMaker/Sibs (ftp://ftpgenome.wi.mit.edu/distribution/software/sibs) and Genehunter Z.O. (http://galton.uchicago.edu/) public softwares.

Chi-square statistics or Fisher's exact test were used for comparisons of the frequencies of CAG repeat polymorphisms in the groups studied. Independent samples $t$-test was used for comparison of lengths of repeat alleles between various groups (SPSS 11.0). A $P$ value of 0.05 or less was considered significant. Correction for multiple comparisons was applied where appropriate.

\section{Results}

\section{Case-control series}

The number of exon 1 CAG repeats identified in cases and controls were between 7 and 28, which corresponds to the normal range (25). The distribution of CAG repeat alleles did not differ significantly between patients (1315 alleles) and the control group (1871 alleles) (Table 1). Similarly, no difference was found when boys were analysed separately. Interestingly, the short repeat alleles (7-14) were more prevalent in girls with diabetes compared with control girls $(8.77 \%$ vs $5.91 \% ; P=0.03$, odds ratio $(\mathrm{OR})$ $1.53,95 \%$ confidence interval (CI) 1.03-2.26); however the difference disappeared when correction 
Table 1 Distribution of androgen receptor gene exon 1 CAG repeat alleles in children with type 1 diabetes and controls.

\begin{tabular}{|c|c|c|c|c|}
\hline \multirow[b]{2}{*}{ Allele } & \multicolumn{2}{|c|}{ Diabetes $(n=1315)$} & \multicolumn{2}{|c|}{ Controls $(n=1871)$} \\
\hline & No. & $\%$ & No. & $\%$ \\
\hline 7 & 1 & 0.08 & 1 & 0.05 \\
\hline 8 & 0 & 0 & 0 & 0 \\
\hline 9 & 1 & 0.08 & 7 & 0.37 \\
\hline 10 & 3 & 0.23 & 2 & 0.11 \\
\hline 11 & 5 & 0.38 & $\overline{6}$ & 0.32 \\
\hline 12 & 9 & 0.68 & 13 & 0.69 \\
\hline 13 & 8 & 0.61 & 5 & 0.27 \\
\hline 14 & 84 & 6.39 & 95 & 5.08 \\
\hline 15 & 91 & 6.92 & 123 & 6.57 \\
\hline 16 & 135 & 10.27 & 190 & 10.15 \\
\hline 17 & 217 & 16.50 & 327 & 17.48 \\
\hline 18 & 185 & 14.07 & 243 & 12.99 \\
\hline 19 & 162 & 12.32 & 235 & 12.56 \\
\hline 20 & 88 & 6.69 & 133 & 7.11 \\
\hline 21 & 159 & 12.09 & 224 & 11.97 \\
\hline 22 & 76 & 5.78 & 141 & 7.54 \\
\hline 23 & 39 & 2.97 & 61 & 3.26 \\
\hline 24 & 28 & 2.13 & 23 & 1.23 \\
\hline 25 & 14 & 1.06 & 31 & 1.66 \\
\hline 26 & 5 & 0.38 & 9 & 0.48 \\
\hline 27 & 1 & 0.08 & 2 & 0.11 \\
\hline 28 & 4 & 0.3 & 0 & 0 \\
\hline
\end{tabular}

for multiple comparisons was applied. Cases were stratified according to age at diagnosis $(0-4.9,5-9.9$ and 10-15 years) and groups were compared with each other and also with controls. No differences were detected (data not shown).

CAG repeat allele frequencies were also compared in HLA DR3-positive cases $(n=562)$ and controls $(n=365)$ and no differences were found either when the whole group or various age at diagnosis groups were compared.

However, when DR3-positive boys with T1D $(n=420)$ were compared with DR3-positive control boys $(n=229)$ the frequency of long repeat alleles (19-28) was reduced in the cases $(32.6 \%$ vs $40.6 \%$; $P=0.011$, OR $0.66,95 \%$ CI $0.47-0.91)$. The corrected $P$ value was not significant. There was no difference between cases and controls when DR3-positive girls were analysed.

When the length of repeat alleles were compared between cases and controls using independent samples $t$-test, no difference was found. Similar comparisons were carried out on groups stratified according to sex, age at onset and HLA genotype, and no differences were seen.

\section{TDT results}

Transmission analysis including the 20 alleles identified in the 765 families was not statistically significant (global $P$ value of 0.06 (extended transmission disequilibrium test (ETDT) 29.3)). However, a decreased transmission of the allele with 20 repeats to cases was observed (T42, NT 72, T\% 36.8; $P=0.005$ ). No significant distortion from expected was seen when transmissions to boys were analysed. In contrast, the transmission of CAG repeat alleles to girls differed from the expected value significantly (ETDT 37.82; $P=0.0016)$. A profoundly decreased transmission of the allele with 20 repeats to girls was observed (T14, NT41, T\%25.5; $P=0.0003)$. In addition, transmissions of alleles with 13 and 26 repeats to affected girls were also decreased (T0, NT4; $P=0.046$; and TO, NT 5, $P=0.025$ respectively). The ETDT finding in girls is mostly explained by the transmission distortion of these three alleles.

\section{Linkage}

Genetic linkage was analysed in sibling pair families using Genehunter 2.0 program, and a LOD score of 1.43 was obtained for the AR exon 1 CAG repeat polymorphism.

\section{Discussion}

In this study we analysed the association and linkage of the androgen receptor gene exon 1 CAG repeat polymorphism with type 1 diabetes in the Finnish population. A combined strategy of case-control and family-based approaches was used. The case-control comparison indicated that the short repeat alleles (7-14) were more prevalent in girls and the long repeat alleles $(19-28)$ were less common in DR3-positive male patients than in controls, although the differences did not remain significant after correction for multiple comparisons. We conclude that the results do not support a common role for this polymorphism in the genetic predisposition to type 1 diabetes.

Interestingly, ETDT showed a profoundly decreased transmission of the repeat allele 20 in girls. It might indicate that it is not the studied AR polymorphism itself but a putative disease variant in linkage disequilibrium with this particular allele which may confer T1D susceptibility. The existence of such a diabetes susceptibility locus on chromosome $\mathrm{X}$ has been suggested, and the AR gene region was also identified in the first T1D genome scan with a maximum LOD score of 1.2 $(3,26)$. We found a similar evidence of linkage in this study. Since a more pronounced disease predisposing effect for the chromosome X T1D locus was indicated in HLA DR3-positive individuals, we analysed transmission of the AR alleles in the HLA DR3-positive family set. No distortion from the expected value could be identified.

We observed no difference in the length of AR repeat alleles between different age at onset and gender groups, which might indicate that androgen action does not contribute to the pubertal peak in disease incidence. 
There is very limited data in the literature on the relationship of AR gene polymorphism and autoimmune diseases. Kawasaki and co-workers (16) found that young-onset male patients with rheumatoid arthritis had significantly shorter CAG repeat lengths than controls (21.8 vs 23.2) and suggested that increased androgen sensitivity could affect disease development. Similarly, shorter exon 1 CAG repeats were found to be more prevalent in patients with ankylosing spondylitis (22 vs 23) in the study of Mori et al. (27). Accordingly, both studies described a shift of AR alleles towards the short repeat range; however the biological significance of the findings is doubtful, since the difference in the allele length between the groups was about one repeat only. We analysed the distribution of the CAG repeat alleles and also compared the length of the alleles in both sexes, in different age at onset groups and also in the HLA DR3 subgroup. However, no differences were found.

In summary, our findings indicate that the AR exon 1 CAG polymorphism does not contribute to T1D susceptibility in Finnish patients. The ETDT results might indicate an effect of a disease variant in linkage disequilibrium and justify further T1D gene mapping efforts in this chromosome region.

\section{References}

1 Whitacre CC. Sex differences in autoimmune disease. Nature Immunology 20012 777-780.

2 Rosmalen JG, Pigmans MJ, Kersseboom R, Drexhage HA Leenen PJ \& Homo-Delarche F. Sex steroids influence pancreatic islet hypertrophy and subsequent autoimmune infiltration in nonobese diabetic (NOD) and NODscid mice. Laboratory Investigation $200181231-239$

3 Cucca F, Goy JV, Kawaguchi Y, Esposito L, Merriman ME, Wilson AJ et al. A male-female bias in type 1 diabetes and linkage to chromosome Xp in MHC HLA-DR3-positive patients. Nature Genetics $199819301-302$.

4 Gale EA \& Gillespie KM. Diabetes and gender. Diabetologia 2001 $443-15$.

5 Brown CJ, Goss SJ, Lubahn DB, Joseph DR, Wilson EM, French FS et al. Androgen receptor locus on the human $\mathrm{X}$ chromosome: regional localization to Xq11-12 and description of a DNA polymorphism. American Journal of Human Genetics $1989 \mathbf{4 4}$ 264-269.

6 Lubahn DB, Joseph DR, Sullivan PM, Willard HF, French FS \& Wilson EM. Cloning of human androgen receptor complementary DNA and localization to the X chromosome. Science 1988240 327-330.

7 Chamberlain NL, Driver ED \& Miesfeld RL. The length and location of CAG trinucleotide repeats in the androgen receptor N-terminal domain affect transactivation function. Nucleic Acids Research 199422 3181-3186.

8 Kazemi-Esfarjani P, Trifiro MA \& Pinsky L. Evidence for a repressive function of the long polyglutamine tract in the human androgen receptor: possible pathogenetic relevance for the (CAG)n-expanded neuronopathies. Human Molecular Genetics $19954523-527$

9 Harkonen K, Huhtaniemi I, Makinen J, Hubler D, Irjala K, Koskenvuo $\mathrm{M}$ et al. The polymorphic androgen receptor CAG repeat, pituitary-testicular function, and andropausal symptoms in ageing men. International Journal of Andrology 20033 187-194.
10 La Spada AR, Roling DB, Harding AE, Warner CL, Spiegel R, Hausmanowa-Petrusewicz I et al. Meiotic stability and genotype-phenotype correlation of the trinucleotide repeat in X-linked spinal and bulbar muscular atrophy. Nature Genetics 19922 301-304.

11 Yong EL, Lim LS, Wang Q, Mifsud A, Lim J, Ong YC et al. Androgen receptor polymorphisms and mutations in male infertility. Journal of Endocrinological Investigation 200023 573-577.

12 Puscheck EE, Behzadian MA \& McDonough PG. The first analysis of exon 1 (the transactivation domain) of the androgen receptor gene in infertile men with oligospermia or azoospermia. Fertility and Sterility $1994 \mathbf{6 2} 1035-1038$.

13 La Spada AR, Wilson EM, Lubahn DB, Harding AE \& Fischbeck KH. Androgen receptor gene mutations in X-linked spinal and bulbar muscular atrophy. Nature 1991352 77-79.

14 Chen C, Lamharzi N, Weiss NS, Etzioni R, Dightman DA, Barnett $\mathrm{M}$ et al. Androgen receptor polymorphisms and the incidence of prostate cancer. Cancer Epidemiology Biomarkers and Prevention 200211 1033-1040.

15 Mifsud A, Ramirez S \& Yong EL. Androgen receptor gene CAG trinucleotide repeats in anovulatory infertility and polycystic ovaries. Journal of Clinical Endocrinology and Metabolism $2000 \mathbf{8 5}$ 3484-3488.

16 Kawasaki T, Ushiyama T, Ueyama H, Inoue K, Mori K, Ohkubo I et al. Polymorphic CAG repeats of the androgen receptor gene and rheumatoid arthritis. Annals of the Rheumatic Diseases 199958 500-502.

17 Fox HS. Androgen treatment prevents diabetes in nonobese diabetic mice. Journal of Experimental Medicine $1992 \mathbf{1 7 5}$ 1409-1412.

18 Morimoto S, Fernandez-Mejia C, Romero-Navarro G, Morales-Peza N \& Diaz-Sanchez V. Testosterone effect on insulin content, messenger ribonucleic acid levels, promoter activity, and secretion in the rat. Endocrinology $2001 \mathbf{1 4 2} 1442-1447$.

19 Hurlbert MS, Zhou W, Wasmeier C, Kaddis FG, Hutton JC \& Freed CR. Mice transgenic for an expanded CAG repeat in the Huntington's disease gene develop diabetes. Diabetes $1999 \mathbf{4 8}$ $649-651$.

20 Soltesz G, Madacsy L, Bekefi D \& Danko I. Rising incidence of type 1 diabetes in Hungarian children (1978-1987). Hungarian Childhood Diabetes Epidemiology Group. Diabetic Medicine 1990 7 111-114.

21 Nystrom L, Dahlquist G, Ostman J. Wall S, Arnqvist H, Blohme G et al. Risk of developing insulin-dependent diabetes mellitus (IDDM) before 35 years of age: indications of climatological determinants for age at onset. International Journal of Epidemiology $199221352-358$.

22 Miller SA, Dykes DD \& Polesky HF. A simple salting out procedure for extracting DNA from human nucleated cells. Nucleic Acids Research 1988161215.

23 Sjoroos M, Iitia A, Ilonen J, Reijonen H \& Lovgren T. Triple-label hybridization assay for type-1 diabetes-related HLA alleles. Biotechniques 199518 870-877.

24 Laaksonen M, Pastinen T, Sjoroos M, Kuokkanen S, Ruutiainen J, Sumelahti ML et al. HLA class II associated risk and protection against multiple sclerosis - a Finnish family study. Journal of Neuroimmunology 2002122 140-145.

25 Edwards A, Hammond HA, Jin L, Caskey CT \& Chakraborty R. Genetic variation at five trimeric and tetrameric tandem repeat loci in four human population groups. Genomics $199212241-253$.

26 Davies JL, Kawaguchi Y, Bennett ST, Copeman JB, Cordell HJ, Pritchard LE et al. A genome-wide search for human type 1 diabetes susceptibility genes. Nature 1994371 130-136.

27 Mori K, Ushiyama T, Inoue K \& Hukuda S. Polymorphic CAG repeats of the androgen receptor gene in Japanese male patients with ankylosing spondylitis. Rheumatology $200039530-532$.

Received 10 April 2003

Accepted 12 August 2003 